\title{
Educational Needs and Resources for Teachers Working with Students with Chronic Pain: Results of a Delphi Study
}

\author{
Elena Castarlenas ${ }^{1,2}$, Rubén Roy ${ }^{1,2}$, Isabel Salvat ${ }^{2,3}$, Pilar Montesó-Curto ${ }^{4}$ and Jordi Miró ${ }^{1,2, *(D)}$ \\ 1 Universitat Rovira i Virgili, Unit for the Study and Treatment of Pain-ALGOS, Research Center for \\ Behavior Assessment (CRAMC), Department of Psychology, 43007 Tarragona, Catalonia, Spain; \\ elena.castarlenas@urv.cat (E.C.); ruben.roy@urv.cat (R.R.) \\ 2 Institut d'Investigació Sanitària Pere Virgili, 43007 Tarragona, Catalonia, Spain \\ 3 Universitat Rovira i Virgili, Unit of Physiotherapy, Department of Medicine and Surgery, \\ 43204 Reus, Catalonia, Spain; mariaisabel.salvat@urv.cat \\ 4 Universitat Rovira i Virgili, Faculty of Nursing, 43500 Tortosa, Catalonia, Spain; mariapilar.monteso@urv.cat \\ * Correspondence: jordi.miro@urv.cat; Tel.: +34-977-55-81-79
}

check for updates

Citation: Castarlenas, E.; Roy, R.; Salvat, I.; Montesó-Curto, P.; Miró, J. Educational Needs and Resources for Teachers Working with Students with Chronic Pain: Results of a Delphi Study. Sustainability 2021, 13, 4510. https://doi.org/10.3390/su13084510

Academic Editor: Giuseppe Battaglia

Received: 19 March 2021

Accepted: 14 April 2021

Published: 19 April 2021

Publisher's Note: MDPI stays neutral with regard to jurisdictional claims in published maps and institutional affiliations.

Copyright: (c) 2021 by the authors. Licensee MDPI, Basel, Switzerland. This article is an open access article distributed under the terms and conditions of the Creative Commons Attribution (CC BY) license (https:// creativecommons.org/licenses/by/ $4.0 /)$.

\begin{abstract}
Children and adolescents spend most of their time at school. Therefore, teachers could be of help to improve the quality of life of students with chronic pain while they are at school. The aim of this study was to identify teachers' educational needs and resources to help improve the adjustment to and function in the school of students with chronic pain. A Delphi survey including two rounds was conducted. Overall, 49 needs were identified in the first round. They were related to education, training, organization/logistics, and communication with the family and the health care center. Among the most important needs, based on the importance given and consensus reached, were (1) having information about the most appropriate attitudes and responses to a student with chronic pain, (2) how to reduce absenteeism, (3) how to ease the return to school after a long absence due to his or her pain problem, and (4) how to establish effective communication with the family. The results of this study provide new important data on the educational needs and resources which teachers would like to have to help their students with chronic pain at school, which could be used to develop educative programs for teachers.
\end{abstract}

Keywords: chronic pain; school; teachers; needs; children; adolescents

\section{Introduction}

Chronic pain is an important public health problem with high prevalence in children and adolescents [1]. According to epidemiological studies conducted in nonclinical samples, about 11-35\% of young people report persistent or chronic pain complaints, with older and female individuals reporting higher prevalence rates [2]. Chronic pain affects children and adolescents' physical and psychosocial well-being, causing disability and substantial interference in their daily routines and activities and having a great impact on developmental contexts [3].

School is one of the main contexts for emotional, cognitive, and social growth for children and adolescents [4]. Therefore, what happens in the school may have a significant influence on a student, contributing to model her/his behaviors and identity development and, in general, promoting children's overall development $[5,6]$. Research has shown that chronic pain has a remarkable negative impact on students' school functioning. For example, students with chronic pain problems report high rates of school absenteeism and difficulties to adequately cope with school demands [7-9], falling behind their healthy classmates in relation to academic achievement and success [10,11]. This could be explained, in part, by the negative influence that chronic pain poses on cognitive functions such as attention, memory, concentration, or information processing [12,13]. In addition, studies show that students with chronic pain have a poorer school-related self-concept [14] and higher levels of cognitive-, behavioral-, 
and psychophysiological-related symptoms of school anxiety in comparison with their peers without chronic pain [15-17]. In addition, there is mounting evidence showing that students with chronic pain usually experience peer victimization, and they have fewer friends, feel more isolated, and are less likely to participate in school and after-school activities in comparison with their healthy peers [18-21].

Importantly, research has shown that teachers are of fundamental importance, facilitating processes and helping to improve the quality of life of students with chronic pain while they are at school [17]. Research has identified some of the barriers that teachers face when trying to help students with chronic pain. For example, difficulties related to the management of high rates of school absenteeism, the attention to students with chronic pain, or the relationship and communication with their parents or guardians [22,23]. However, there is not any study focusing on the educational needs and resources that teachers have to attend to and with which to help their students with chronic pain. The information gathered by this study could provide the basis for an educational program for teachers to improve their knowledge about chronic pain in children and adolescents and its management while at school.

Given these considerations, the aim of this study was to (1) better understand the educational needs that teachers have at school when working with students with chronic pain, (2) identify the resources that could help teachers to improve the adjustment to and function in the school of students with chronic pain, and (3) identify the perceived need of educative programs for teachers who work with students with chronic pain. Given previous research findings, we hypothesized that teachers would identify educational and training resources to deal better with the circumstances arising from having students with chronic pain in the classroom as a central need. We also hypothesized that the educational needs showing a higher consensus would be related to receiving training about techniques and strategies to be implemented in the classroom, and how to improve communication with family and health care professionals. Finally, we expected that a vast majority of the participants $(\geq 90 \%$ ) would consider it important to educate teachers on chronic pain and how to better help students with chronic pain conditions.

\section{Materials and Methods}

\subsection{The Study Design}

We used the Delphi method to address the objectives of the study. This method has been proven to be a reliable and valid procedure to achieve a consensus when dealing with difficult questions, more so than other prognostication procedures [24]. It implies identifying a panel of experts and asking them about their opinion on the topic of interest in sequential anonymous rounds until the consensus is reached [25]. For example, the Delphi method has been successfully used on important related issues such as identifying predictive factors of chronic pain and disability in children and adolescents [26], and in whiplash patients [27], and to identify the needs of adolescents and young adult cancer survivors [28].

\subsection{Identification of Participants in the Expert Panel}

The expert panel was intended to include people most knowledgeable about the topic of interest, and for this purpose, we invited to participate two groups of stakeholders:

1. Researchers involved in the management of students with chronic pain. In order to be invited to the study, potential participants had to be actively conducting research on issues related to the management of chronic pain in the school setting or topics closely related such as teachers' attitudes about pain or the impact of chronic pain on school and academic performance of adolescents. We identified 57 potential participants from several countries and research groups by conducting a detailed review of the literature through the most common databases (i.e., Medline, CINAHL, PsycINFO, and ERIC). Then, we emailed them an invitation to participate in the Delphi study. 
2. Teachers who have or have had students with chronic pain in their classes. In order to identify potential participants in this group, we requested the support of the Department of Education of the Government of Catalonia to contact schools in the province of Tarragona (Catalonia, Spain). Along with their support, we sent a letter with a detailed explanation of the study and a request for their help to share the information about the study with their teachers. Following schools' acceptance, we sent a link to the first-round survey to be shared with their teachers. Those that were interested in participating would find a detailed explanation (the same as the schools received) before participating in the study. In addition, we also shared the information about the study on social networks (i.e., Facebook) with specific groups of teachers and educators. In both cases, the inclusion criteria to participate in the study was having been a teacher of students with chronic pain.

Our goal was to recruit, at least, 30 stakeholders, from any of the two groups, which has been identified enough for this type of study [29]. This process lasted two months.

\subsection{Procedure}

Two rounds were needed to reach a consensus.

Round I: Potential participants were sent an email with a detailed description of the purposes of the study, and a brief description of the Delphi method to be used. Before participating, these individuals had to agree to participate in the study. Then, they could proceed and begin answering the survey. First, some sociodemographic information was requested for descriptive purposes. Then, all participants were presented with an open-ended question asking about the needs that teachers have at school to help students with chronic pain, and the resources that would help them improve the adjustment to and function in the school of students with chronic pain, requiring free-text answers (specifically, they were requested to "List the needs that you think teachers might have when they have students with chronic pain in the classroom (e.g., information, training, resources, etc."). They were also asked about the importance of providing teachers with a training program to help young people with pain in an educational setting. They had to answer using a $0-4$ numerical rating scale $(0=$ "not important at all" to $4=$ "extremely important"). It was estimated a duration of about $45 \mathrm{~min}$ to complete this first round. Two reminders were sent to participants to request their collaboration in the study. The needs identified by participants from both groups of stakeholders were qualitatively analyzed and categorized, following semantical criteria, independently by two of the authors (E.C. and R.R.).

Round II: Panelists who completed the first round were contacted again after the first round had been completed and answers analyzed. They received the list of needs, based on responses from participants in round I. They were asked to rate each statement (describing the need or resource) in the list based on their perceived importance, on a 0 to 10 rating scale $(0=$ not at all important; $10=$ extremely important $)$. The completion of this second round took about 15 minutes.

The Delphi method requires that the iterative procedure is repeated until participants' responses reach stability (or when a point of diminishing returns is reached) [29]. In this study, we used the stability of responses as the criterion to consider that a consensus had been reached on any given statement [30]. Stability was reached after two rounds (see the Section 3), which is consistent with findings in similar Delphi studies [24,31]. Consensus about the importance of any of the statements was reached when $75 \%$ of the participants rated it with at least a 7 .

\section{Results}

\subsection{Round I}

In total, 61 (79\% females, $21 \%$ males) completed the first round. All of them were experienced professionals in their field reporting a mean of 13.12 years of professional experience.

A total of 49 statements were identified after coding the responses given by participants to the opening question. They were grouped into three categories labeled (1) "Education/training," which comprises the educational needs related to (a) receiving information 
about theoretical and applied knowledge about pain and (b) learning how to manage painrelated difficulties while in the school setting; (2) "Organization/logistic issues," which alludes to the needs and the resources about school policies and administrative issues and available resources; and (3) "Communication with the family and the health care center," which involves ways to establish an effective and ongoing cooperative relationship between the family, the school, and the health care system. The first category is related to educational needs, whereas the second and third categories also encompass the resources that could help to improve the management of chronic pain in the school setting. Table 1 shows the educational needs and/or the resources included in each category.

Table 1. Number and percentage of participants giving a rating of 7 or higher to the needs in the list.

\begin{tabular}{|c|c|}
\hline TRAINING/EDUCATION & $\mathbf{N}(\%)$ \\
\hline \multicolumn{2}{|l|}{ Theoretical knowledge about pain: Receiving information on ... } \\
\hline 1. The role that teachers and school personal might have in improving chronic pain management; & $34(100)$ \\
\hline 2. The effects of chronic pain on the social domain; & $33(97)$ \\
\hline 3. The more usual nonpharmacological treatments for chronic pain; & $31(95)$ \\
\hline 4. Myths about pain in children and adolescents; & $32(94)$ \\
\hline 5. The effects of chronic pain on the school domain; & $32(94)$ \\
\hline 6. The effects of chronic pain on the emotional domain; & $32(94)$ \\
\hline 7. The biological, psychological, and social factors that influence the experience of chronic pain; & $32(94)$ \\
\hline 8. The effects of chronic pain on the cognitive domain; & $31(92)$ \\
\hline 9. The more common pharmacological treatments and their effects on the cognitive domain; & $29(85)$ \\
\hline 10. The physiology of chronic pain; & $28(82)$ \\
\hline 11. The effects of chronic pain on the physical domain; & $27(79)$ \\
\hline 12. The difference between acute and chronic pain; & $27(79)$ \\
\hline 13. The effects of chronic pain on the family domain; & $27(79)$ \\
\hline 14. The variable course of pain; & $26(76)$ \\
\hline 15. The epidemiology of pediatric chronic pain; & $24(71)$ \\
\hline 16. The diseases usually comorbid with chronic pain; & $24(71)$ \\
\hline 17. The process through which pain becomes chronic. & $19(56) *$ \\
\hline \multicolumn{2}{|l|}{ Applied knowledge about pain: Receiving information on ... } \\
\hline 18. The most appropriate attitudes and responses toward a student with chronic pain; & $33(97)$ \\
\hline 19. How to interact with students with chronic pain (empathy, cordiality); & $33(97)$ \\
\hline 20. How to provide emotional support to children with chronic pain (i.e., listening to the children's problems); & $33(97)$ \\
\hline 21. How to balance the needs of students with chronic pain with the needs of the rest of the class; & $32(94)$ \\
\hline 22. How to prevent pain episodes (i.e., instructing the student not to carry too much weight); & $28(82)$ \\
\hline 23. How to perform diaphragmatic breathing techniques; & $25(73)$ \\
\hline 24. How to perform positive self-instruction techniques; & $25(74)$ \\
\hline $\begin{array}{l}\text { 25. The signs and lines of evidence that indicate the presence of chronic pain (i.e., groans, behaviors to protect the affected } \\
\text { body area, etc.): }\end{array}$ & $24(71)$ \\
\hline 26. How to perform mindfulness techniques; & $23(68) *$ \\
\hline 27. Tools to assess certain features related to chronic pain (i.e., pain intensity); & $20(59) *$ \\
\hline 28. Training teachers to administer medication. & $13(38) *$ \\
\hline \multicolumn{2}{|l|}{ Management of associated difficulties: Learning how to ... } \\
\hline 29. Reduce absenteeism among children with chronic pain; & $34(100)$ \\
\hline 30. Manage problematic behaviors by children with chronic pain; & $33(97)$ \\
\hline 31. Improve the academic performance of children with chronic pain; & $32(94)$ \\
\hline 32. Manage classmates' reactions toward students with chronic pain; & $30(88)$ \\
\hline 33. Facilitate the interaction between students with chronic pain and peers; & $30(88)$ \\
\hline 34. Determine when a student should go home because of the pain. & $30(88)$ \\
\hline \multicolumn{2}{|l|}{ ORGANIZATION/LOGISTICS } \\
\hline 35. How to design and plan the child's return to school after a long absence; & $34(100)$ \\
\hline $\begin{array}{l}\text { 36. The importance of being reasonably flexible about rules in class during a pain episode (i.e., let the student go to the toilet } \\
\text { if necessary, to get up if his or her back hurts, etc.); }\end{array}$ & $31(91)$ \\
\hline 37. Which changes can be made to improve the comfort of children with chronic pain (i.e., providing comfortable chairs); & $31(91)$ \\
\hline $\begin{array}{l}\text { 38. The importance of being reasonably flexible regarding the academic performance of children with chronic pain (e.g., } \\
\text { curriculum variations, changes to deadlines, workload, etc.); }\end{array}$ & $31(91)$ \\
\hline 39. Having information and access to resources on chronic pain & $31(91)$ \\
\hline 40. Receiving support from the government to facilitate the integration and adaptation of students with chronic pain; & $29(85)$ \\
\hline 41. Having extra time to offer individualized attention to those students with chronic pain if necessary; & $27(79)$ \\
\hline 42. Having a learning support teacher in class if necessary; & $26(77)$ \\
\hline 43. Having health care professionals at school. & $20(59) *$ \\
\hline
\end{tabular}


Table 1. Cont

\begin{tabular}{|c|c|}
\hline TRAINING/EDUCATION & $\mathbf{N}(\%)$ \\
\hline \multicolumn{2}{|l|}{ COMMUNICATION WITH THE FAMILY AND THE HEALTH CARE CENTER } \\
\hline 44. To establish good communication between the school and the family regarding the child's specific needs at school; & $34(100)$ \\
\hline $\begin{array}{l}\text { 45. To establish good communication between the school and the health care center regarding the child's specific needs at } \\
\text { school; }\end{array}$ & $32(94)$ \\
\hline 46. Being able to ask for advice from health care professionals external to the school; & $31(92)$ \\
\hline $\begin{array}{l}\text { 47. Having a system that allows the teacher to communicate what has been covered in class to students who have missed } \\
\text { school due to pain; }\end{array}$ & $31(92)$ \\
\hline 48. Making the teacher part of the multidisciplinary team that is treating the student with chronic pain; & $31(91)$ \\
\hline $\begin{array}{l}\text { 49. Establishing some sort of shared record between the school and health professionals to record the student's data (i.e., the } \\
\text { nature and source of pain). }\end{array}$ & $27(79)$ \\
\hline
\end{tabular}

* Statements that did not reach a consensus about their importance.

Providing a training program to support teachers to help their students with chronic pain while at school was perceived as a very useful resource by participating teachers (mean $=3.27 ; \mathrm{SD}=0.67$; range $=0-4)$.

\subsection{Round II}

In the second round, $34(56 \%)$ of the panelists who participated in the first round responded.

A total of 44 items $(89 \%)$ were rated with 7 or more by at least $75 \%$ of the panelists (see Table 1), thus showing a consensus about their importance. The statements with the highest consensus (i.e., between $90 \%$ and $100 \%$ of panelists giving them a rating of 7 or more) were (1) in the category "Education/training": "Myths about pain in children and adolescents"; "The more usual nonpharmacological treatments for chronic pain"; "The biological, psychological, and social factors that influence the experience of chronic pain"; "The effects of chronic pain on the emotional, social, cognitive, and school domain"; "The role that teachers and school personal might have in improving chronic pain management"; "The most appropriate attitudes and responses toward a student with chronic pain"; "How to interact with students with chronic pain (empathy, cordiality)"; "How to provide emotional support to children with chronic pain (i.e., listening to the children's problems)" "How to balance the needs of students with chronic pain with the needs of the rest of the class"; "Manage problematic behaviors by children with chronic pain"; "Reduce absenteeism among children with chronic pain"; and "Improve the academic performance of children with chronic pain"; (2) in the category "Organization/logistics issues": "The importance of being reasonably flexible about rules in class during a pain episode"; "Which changes can be made to improve the comfort of children with chronic pain"; "The importance of being reasonably flexible regarding the academic performance of children with chronic pain"; "How to design and plan the child's return to school after a long absence"; and "Having information and access to resources on chronic pain"; and (3) in the category of "Communication with the family and the health care center": "To establish good communication between the school and the family regarding the child's specific needs at school"; "To establish good communication between the school and the health care center regarding the child's specific needs at school"; "Being able to ask for advice from health care professionals external to the school"; "Making the teacher part of the multidisciplinary team that is treating the student with chronic pain"; and "Having a system that allows the teacher to communicate what has been covered in class to students who have missed school due to pain."

The following statements did not reach a consensus about their importance: "The process through which pain becomes chronic"; "Tools to assess certain features related to chronic pain"; "Learning how to perform mindfulness techniques"; "Training teachers to administer medication"; and "Having health care professionals at school". 


\section{Discussion}

The results of this study provide new data regarding the educational needs and resources that would be of help to teachers with students with chronic pain in their classes. In addition, this research studied the resources that teachers can use to help students with chronic pain achieve their best potential, thus improving and expanding previous findings [22,23]. The participation of a diverse body of stakeholders in this consensus study increased the value of the results by bringing a wider perspective on the problem [28]. On the one hand, we collected information from teachers who provided us first-hand information as to the situation on the ground. In addition, we also obtained information from clinicians and researchers due to their experience in clinical and research contexts, contributing to a better understanding of the needs that teachers face in the school setting.

Most of the needs and concerns identified in this study were related to teacher's education about the nature and characteristics of chronic pain experience and their implications in children's function. Teachers request education both on theoretical issues and applied knowledge about chronic pain, such as how to prevent pain episodes, how to provide emotional support, or how to help them using some psychological techniques for reducing anxiety and discomfort. Learning how to interact with children with chronic pain and what type of responses and attitudes are more adaptive emerged as a special topic of interest. This is of special relevance granted the findings on the association between significant others' reactions (from parents, or schoolmates) and someone's pain behavior and related disability [32,33]. Research on teachers' responses to students' pain-related behaviors has shown that some of these reactions (i.e., solicitousness) are associated with the maintenance of pain and related disability [22,34-36]. Therefore, being able to differentiate which responses may have positive or negative consequences is an important challenge that must be addressed. For example, Vervoort et al. [21] found that school absenteeism was less of a problem among students with chronic pain who perceived their teacher to be highly supportive of their competence and autonomy.

Our results are in concordance with those obtained in the studies conducted by Logan and Curran [23] and Solé et al. [22], who showed that teachers often report some barriers that interfere in their helping the students to mitigate the negative impact of pain. For example, Logan and Curran [23], using a focus group methodology, examined school personnel's understanding of youth's chronic pain and identified some situations difficult to manage related to this situation. Specifically, school personnel reported difficulties to address high rates of school absenteeism, understand the great variability of chronic pain conditions and their symptomatology, adapt school policies to the needs of these youth with chronic pain, attend adequately to the needs of other students, or deal with parents. The study conducted by Solé et al. [22] also identified the most common problems that teachers face when having students with chronic pain and the sources of help that could be of interest for teachers to support these scholars. In this study, absenteeism emerged again as the most problem they should cope with, followed by the negative effect of pain on the ability of students to engage in academic activities.

The findings of these studies show the importance of identifying strategies to improve communication with families in order to help ensure adequate management of chronic pain problems and associated difficulties while children are at school. Effective communication between all the actors involved has important advantages that could improve the quality of life and functioning of children with chronic pain. For example, it ensures the opportunity for families and teachers to exchange concerns and expectations, share goals, and participate actively in the decision-making progress of all related to the issues to the academic functioning of these youth with chronic pain [37].

There are some limitations in the current study that should de acknowledged. First, data have been analyzed without taking into account the educational stages. Future studies should examine whether the needs that teachers face in each educational level are different and how these differences should be addressed. Second, panelists were a group of individuals that were motivated to participate and included just a few secondary 
school teachers. We do not know the extent to which the sample is representative. It would be important to replicate the study with additional samples of stakeholders, including secondary school teachers with experience working with a diversity of students with chronic pain. Third, our sample did not include other school personnel beyond teachers. Thus, future research could examine the perceptions of this other personnel (e.g., school's custodians, school lunch monitors, or instructors of complementary and extracurricular activities), to explore their position and how this could be integrated with the educative programs for teachers.

Despite the study's limitations, this study provides new important information on the needs that teachers face when working with students with chronic pain. The findings show that teachers need specific training and education about the nature and impact of chronic pain in all the domains of the students' life, the strategies to improve their interaction with students with chronic pain, and the resources to improve communication with families and healthcare professionals. The influence of pain education is well known. For example, there is mounting evidence showing that explaining pain to individuals with chronic pain can change pain-related attitudes and catastrophic thinking about pain, which, in turn, can help improve physical, psychological, and social function [38]. In the case of teachers, they might understand better what chronic pain is and the impact on their students' functioning, and even more important, they will have a better understanding of how to react when interacting with students with chronic pain. It will also bring personal benefits, such as an increased perception of self-competence and self-confidence, which, in turn, can improve teachers' well-being and personal satisfaction [39]. Research has shown that effective communication is key for a patient's satisfaction and improving her or his function $[40,41]$. Moreover, poor communication has been found to be related to deteriorated patients' compliance [42]. Therefore, improving teacher-student-health care communication can lead to greater compliance and benefits for all stakeholders involved.

\section{Conclusions and Further Research}

To our knowledge, this is the first study that has used the Delphi method to reach a consensus about the educational needs and resources that teachers have when working with students with chronic pain. The findings of this study provide information that could be used to help develop educative programs for teachers. However, it is unclear what would be the most appropriate content and strategies to educate teachers. Therefore, future research on what are the most effective procedures to provide this education and training to teachers is warranted. For example, research is needed to determine the usability and efficacy of educative materials. Moreover, it is also of interest to study what internal and external personal characteristics of the actors influence the results of these educative programs. For example, studying whether these educative programs enhance teachers' selfefficacy expectancies to manage the problems they encounter when helping students with chronic pain, or if they feel more competent and satisfied after receiving this education.

Author Contributions: Conceptualization: E.C., R.R., I.S., P.M.-C., and J.M.; methodology, E.C., R.R., and J.M.; formal analysis, E.C. and R.R.; writing-original draft preparation, E.C. and J.M.; writing-review and editing, E.C., R.R., I.S., P.M.-C., and J.M.; funding acquisition, E.C., R.R., I.S., P.M.-C., and J.M. All authors have read and agreed to the published version of the manuscript.

Funding: This research was funded in part by grant PSI2014-60180-JIN of the Spanish Ministry of Economy and Competitiveness. Additional support was provided by grants from the Spanish Ministry of Economy, Industry, and Competitiveness (RTI2018-09870-B-I00; RED2018-102546-T), the European Regional Development Fund (ERDF), the Government of Catalonia (AGAUR; 2017SGR1321), and Universitat Rovira i Virgili (PFR program). J.M.'s work is supported by Fundación Grünenthal (Spain), and ICREA-Acadèmia.

Institutional Review Board Statement: The study was conducted according to the guidelines of the Declaration of Helsinki, and approved by the Department of Education of the Government of Catalonia and the Spanish Ministry of Economy and Competitiveness (PSI2014-60180-JIN). 
Informed Consent Statement: Informed consent was obtained from all subjects involved in the study.

Data Availability Statement: The dataset used and analyzed in this study is available from the corresponding author upon request.

Conflicts of Interest: The authors declare no conflict of interest. The funders had no role in the design of the study; in the collection, analyses, or interpretation of data; in the writing of the manuscript, or in the decision to publish the results.

\section{References}

1. Huguet, A.; Miró, J. The severity of chronic pediatric pain: An epidemiological study. J. Pain 2008, 9, 226-236. [CrossRef]

2. King, S.; Chambers, C.T.; Huguet, A.; MacNevin, R.C.; McGrath, P.J.; Parker, L.; MacDonald, A.J. The epidemiology of chronic pain in children and adolescents revisited: A systematic review. Pain 2011, 152, 2729-2738. [CrossRef]

3. Haraldstad, K.; Christophersen, K.A.; Helseth, S. Health-related quality of life and pain in children and adolescents: A school survey. BMC Pediatr. 2017, 17, 174. [CrossRef]

4. $\quad$ Eccles, J.S.; Roeser, R.W. Schools as developmental contexts during adolescence. J. Res. Adolesc. 2011, 21, 225-241. [CrossRef]

5. Verhoeven, M.; Poorthuis, A.M.G.; Volman, M. The Role of School in Adolescents' Identity Development. A Literature Review. Educ. Psychol. Rev. 2019, 31, 35-63. [CrossRef]

6. Lannegrand-Willems, L.; Bosma, H.A. Identity development-in-context: The school as an important context for identity development. Identity 2006, 6, 85-113. [CrossRef]

7. Groenewald, C.B.; Giles, M.; Palermo, T.M. School Absence Associated with Childhood Pain in the United States. Clin. J. Pain 2019, 35, 525-531. [CrossRef]

8. Simons, L.E.; Logan, D.E.; Chastain, L.; Stein, M. The relation of social functioning to school impairment among adolescents with chronic pain. Clin. J. Pain 2010, 26, 16-22. [CrossRef] [PubMed]

9. Agoston, A.; Gray, L.; Logan, D. Pain in School: Patterns of Pain-Related School Impairment among Adolescents with Primary Pain Conditions, Juvenile Idiopathic Arthritis Pain, and Pain-Free Peers. Children 2016, 3, 39. [CrossRef] [PubMed]

10. Kosola, S.; Mundy, L.K.; Sawyer, S.M.; Canterford, L.; Van Der Windt, D.A.; Dunn, K.M.; Patton, G.C. Pain and learning in primary school: A population-based study. Pain 2017, 158, 1825-1830. [CrossRef] [PubMed]

11. Ragnarsson, S.; Myleus, A.; Hurtig, A.K.; Sjöberg, G.; Rosvall, P.Å.; Petersen, S. Recurrent Pain and Academic Achievement in School-Aged Children: A Systematic Review. J. Sch. Nurs. 2020, 36, 61-78. [CrossRef] [PubMed]

12. Weiss, K.E.; Harbeck-Weber, C.; Zaccariello, M.J.; Kimondo, J.N.; Harrison, T.E.; Bruce, B.K. Executive functioning in pediatric chronic pain: Do deficits exist? Pain Med. 2018, 19, 60-67. [CrossRef]

13. Dick, B.D.; Riddell, R.P. Cognitive and school functioning in children and adolescents with chronic pain: A critical review. Pain Res. Manag. 2010, 15, 238-244. [CrossRef]

14. Logan, D.E.; Gray, L.S.; Iversen, C.N.; Kim, S. School self-concept in adolescents with chronic pain. J. Pediatr. Psychol. 2017, 42, 892-901. [CrossRef]

15. Gibler, R.C.; Beckmann, E.A.; Lynch-Jordan, A.M.; Kashikar-Zuck, S.; Mano, K.E.J. Characterizing Social and Academic Aspects of School Anxiety in Pediatric Chronic Pain. Clin. J. Pain 2019, 35, 625-632. [CrossRef] [PubMed]

16. Jastrowski Mano, K.E. School Anxiety in Children and Adolescents with Chronic Pain. Pain Res. Manag. 2017, 2017. [CrossRef] [PubMed]

17. Khan, K.A.; Tran, S.T.; Jastrowski Mano, K.E.; Simpson, P.M.; Cao, Y.; Hainsworth, K.R. Predicting Multiple Facets of School Functioning in Pediatric Chronic Pain. Clin. J. Pain 2015, 31, 867-875. [CrossRef] [PubMed]

18. Forgeron, P.A.; King, S.; Stinson, J.N.; McGrath, P.J.; MacDonald, A.J.; Chambers, C.T. Social functioning and peer relationships in children and adolescents with chronic pain: A systematic review. Pain Res. Manag. 2010, 15, 27-41. [CrossRef]

19. Greco, L.A.; Freeman, K.E.; Dufton, L. Overt and relational victimization among children with frequent abdominal pain: Links to social skills, academic functioning, and health service use. J. Pediatr. Psychol. 2007, 32, 319-329. [CrossRef]

20. Fales, J.L.; Murphy, L.K.; Rights, J.D.; Palermo, T.M. Daily Peer Victimization Experiences of Adolescents With and Without Chronic Pain: Associations With Mood, Sleep, Pain, and Activity Limitations. J. Pain 2020, 21, 97-107. [CrossRef] [PubMed]

21. Vervoort, T.; Logan, D.E.; Goubert, L.; De Clercq, B.; Hublet, A. Severity of pediatric pain in relation to school-related functioning and teacher support: An epidemiological study among school-aged children and adolescents. Pain 2014, 155, 1118-1127. [CrossRef] [PubMed]

22. Solé, E.; Castarlenas, E.; Sánchez-Rodríguez, E.; Galán, S.; de la Vega, R.; Jensen, M.P.; Miró, J. Chronic Pain in the School Setting: The Teachers' Point of View. J. Sch. Health 2018, 88, 65-73. [CrossRef] [PubMed]

23. Logan, D.E.; Curran, J.A. Adolescent chronic pain problems in the school setting: Exploring the experiences and beliefs of selected school personnel through focus group methodology. J. Adolesc. Health 2005, 37, 281-288. [CrossRef] [PubMed]

24. Graham, B.; Regehr, G.; Wright, J.G. Delphi as a method to establish consensus for diagnostic criteria. J. Clin. Epidemiol. 2003, 56, 1150-1156. [CrossRef]

25. Diamond, I.R.; Grant, R.C.; Feldman, B.M.; Pencharz, P.B.; Ling, S.C.; Moore, A.M.; Wales, P.W. Defining consensus: A systematic review recommends methodologic criteria for reporting of Delphi studies. J. Clin. Epidemiol. 2014, 67, 401-409. [CrossRef] 
26. Miró, J.; Huguet, A.; Nieto, R. Predictive factors of chronic pediatric pain and disability: A Delphi poll. J. Pain 2007, 8, 774-792. [CrossRef]

27. Miró, J.; Nieto, R.; Huguet, A. Predictive factors of chronic pain and disability in whiplash: A Delphi poll. Eur. J. Pain 2008, 12, 30-47. [CrossRef]

28. Galán, S.; de la Vega, R.; Tomé Pires, C.; Racine, M.; Solé, E.; Jensen, M.P.; Miró, J. What are the needs of adolescents and young adults after a cancer treatment? A Delphi study. Eur. J. Cancer Care 2017, 26, e12488. [CrossRef]

29. Hasson, F.; Keeney, S.; McKenna, H. Research guidelines for the Delphi survey technique. J. Adv. Nurs. 2000, 32, $1008-1015$.

30. Okoli, C.; Pawlowski, S.D. The Delphi method as a research tool: An example, design considerations and applications. Inf. Manag. 2004, 42, 15-29. [CrossRef]

31. Llorens-Vernet, P.; Miró, J. The mobile app development and assessment guide (MAG): Delphi-Based validity study. JMIR mHealth uHealth 2020, 8, e17760. [CrossRef] [PubMed]

32. Miró, J.; de la Vega, R.; Gertz, K.J.; Jensen, M.P.; Engel, J.M. The role of perceived family social support and parental solicitous responses in adjustment to bothersome pain in young people with physical disabilities. Disabil. Rehabil. 2019, 41, 641-648. [CrossRef]

33. Huguet, A.; Miró, J.; Nieto, R. The inventory of parent/caregiver responses to the children's pain experience (IRPEDNA): Development and preliminary validation. Pain 2008, 134, 128-139. [CrossRef] [PubMed]

34. Castarlenas, E.; de la Vega, R.; Tomé-Pires, C.; Solé, E.; Racine, M.; Jensen, M.P.; Miró, J. Student Expectations of Peer and Teacher Reactions to Students With Chronic Pain: Implications for Improving Pain-related Functioning. Clin. J. Pain 2015, 31, 992-997. [CrossRef] [PubMed]

35. Logan, D.E.; Catanese, S.P.; Coakley, R.M.; Scharff, L. Chronic pain in the classroom: Teachers' attributions about the causes of chronic pain. J. Sch. Health 2007, 77, 248-256. [CrossRef] [PubMed]

36. Logan, D.E.; Coakley, R.M.; Scharff, L. Teachers' perceptions of and responses to adolescents with chronic pain syndromes. J. Pediatr. Psychol. 2007, 32, 139-149. [CrossRef]

37. Christenson, S.L. The Family-School Partnership: An Opportunity to Promote the Learning Competence of All Students. School Psych. Rev. 2004, 33, 83-104. [CrossRef]

38. Gallagher, L.; McAuley, J.; Moseley, G.L. A randomized-controlled trial of using a book of metaphors to reconceptualize pain and decrease catastrophizing in people with chronic pain. Clin. J. Pain 2013, 29, 20-25. [CrossRef]

39. Coccia, C.C.; Tamargo, J.; Macchi, A.K. Effects of nutrition knowledge, personal health and self-efficacy on food-related teaching practices of elementary school pre-service teachers. Health Educ. J. 2020, 79, 974-986. [CrossRef]

40. Kim, S.S.; Kaplowitz, S.; Johnston, M.V. The effects of physician empathy on patient satisfaction and compliance. Eval. Health Prof. 2004, 27, 237-251. [CrossRef]

41. Burgener, A.M. Enhancing Communication to Improve Patient Safety and to Increase Patient Satisfaction. Health Care Manag. 2017, 36, 238-243. [CrossRef] [PubMed]

42. Haskard Zolnierek, K.B.; Dimatteo, M.R. Physician communication and patient adherence to treatment: A meta-analysis. Med. Care 2009, 47, 826-834. [CrossRef] [PubMed] 